\title{
MELHORAMENTO DO TRIGO: XXV. AVALIAÇÃO DE GENÓTIPOS ORIUNDOS DE POPULAÇOOES HÍBRIDAS INTRODUZIDAS DE OREGON (EUA) NO ESTADO DE SÃO PAULO ( $\left.{ }^{1}\right)$
}

\author{
CARLOS EDUARDO DE OLIVEIRA CAMARGO $(2,7)$, JOÃO CARLOS FELICIO $(2,7)$, \\ ANTONIO WILSON PENTEADO FERREIRA FILHO $(2,7)$, BENEDITO \\ DE CAMARGO BARROS $(3,7)$, JOSÉ GUILHERME DE FREITAS $\left.{ }^{2,7}\right)$, \\ ARMANDO PETTINELLI JÚNIOR ( $\left.{ }^{4}\right)$, PAULO BOLLER GALLO (5) \\ e RICARDO AUGUSTO DIAS KANTHACK $(\hat{)})$
}

\begin{abstract}
RESUMO
Foram comparadas entre si vinte e duas linhagens e três cultivares $(\mathrm{BH}-1146$, IAC-18 e Alondra-S-46) em seis ensajos, instalados nas Estaçőes Experimentais de Tatuí (1985-87) e Mococa (1984), no Centro Experimental de Campinas (1985) e na Fazenda Nossa Senhora da Penha (1986), município de Florínea, em condiçöes de irrigação por aspersão, analisando-se os seguintes parâmetros: rendimento de grãos, características agronômicas e resistência às doenças. Em casa de vegetação, efetuaram-se estudos de resistência às misturas de raças prevalecentes dos agentes causais da ferrugem-do-colmo e da-folha e, em condiçōes de laboratório, estudos da tolerância ao alumínio, em soluçöes nutritivas. Em solos corrigidos de Tatuí, a linhagem 1 (Novi Sad 738/Bluejay), sensível à toxicidade de $\mathrm{A}^{3+}$, de porte baixo, ciclo precoce, destacou-se quanto à produção de grãos. Em solo ácido, de Mococa, os cultivares $\mathrm{BH}-1146$ e IAC-18, tolerantes à toxicidade de $\mathrm{A}^{3+}$, de porte alto e ciclo precoce, foram os mais produtivos. As linhagens 1, 3 (Yaktana 54/Norin 10 - Brevor//Narino 59/3/Hyslop/4/CIANO/Gallo) e 19 (Capitole/Bluetit) e os cultivares BH-1146 e IAC-18 destacaram-se quanto à produção de grãos, considerando-se a média dos seis ensaios. As linhagens 2 (Leonardo 23/Bluejay) e 10 (Backa/Alondra) foram resistentes às duas misturas de raças testadas da ferrugem-do-colmo e às três misturas de raças da ferrugem-da-folha, em estádio de plântula, confirmando esta resistência em condições de infecção natural no estádio de planta adulta. A linhagem 2 mostrou-se moderadamente resistente ao oídio. As linhagens 11 (Backa/Alondra), 15 e 21 (Capi-
\end{abstract}

(') Com verba suplementar do Acordo do Trigo entre as Cooperativas de Produtores Rurais do Vale do Paranapanema e a Secretaria da Agricultura, por intermédio do Instituto Agronômico. Recebido para publicação em 20 de novembro de 1990 e aceito em 21 de janeiro de 1992.

(2) Seção de Arroz e Cereais de Inverno, Instituto Agronômico (IAC), Caixa Postal 28, 13001 Campinas, SP.

(3) Seção de Doenças das Plantas Alimentícias Básicas e Olerícolas, Instituto Biológico (IB), 13093 Campinas, SP.

(4) Estação Experimental de Tatuí, IAC.

(5) Estação Experimental de Mococa, IAC.

(6) Estação Experimental de Assis, IAC.

(7) Com bolsa de pesquisa do CNPq. 
tole/Bluetit), 16 (Sava/4/Tezanos Pintos Precoz//IRN 46/ClANO/3/Protor) e 17 (Nogel Selection 29/Nogel Selection 59-8881//INIACaprock/3/Cuckoo) foram as mais tolerantes à toxicidade de $\mathrm{A}^{3+}$, porém num grau menor do que os exibidos pelos cultivares $\mathrm{BH}-1146$ e IAC-18.

Termos de indexação: trigo; cultivar; linhagens; produção de grãos; altura das plantas; ferrugem-do-colmo e da-folha; tolerância, toxicidade de alumínio.

\section{ABSTRACT \\ WHEAT BREEDING: XXV. EVALUATION OF GENOTYPES OBTAINED FROM HYBRID POPULATIONS INTRODUCED FROM OREGON, U.S.A., IN THE STATE OF SÃO PAULO, BRAZIL}

Twenty two inbred lines and three cultivars (BH-1146, IAC-18 and Alondra-S-46) were evaluated in trials carried out with sprinkler irrigation, at Tatuí (1985-87) and Mococa (1984) Experimental Station, Campinas (1985) Experimental Center and in a private farm located in Florínea. The following parameters were assessed: grain yield, agronomic characteristics and disease resistance. Tests for resistance to stem and leaf rusts and to aluminum tolerance, were made in greenhouse and laboratory, respectively. In soil with high fertility conditions as in Tatuí the line 1 (Novi Sad 738 /Bluejay) which is sensitive to $\mathbf{A}^{3+}$ toxicity, early maturity and semidwarf type, showed good grain yield. Under acid soil conditions, at Mococa, the cultivars $\mathrm{BH}-1146$ and $\mathrm{IAC}-18$, presenting tolerance to $\mathrm{A}^{3+}$ toxicity, early maturity and tall type, were the most productive. The lines 1, 3 (Yaktana-54/Norin 10-Brevor//Narino 59/3/HysIop/4/CIANO/Gallo) and 19 (Capitole/Bluetit) and the cultivars BH-1146 and IAC-18 showed the best grain yield considering the mean of the six trials. The lines 2 (Leonardo 23/Bluejay) and 10 (Backa/Alondra) were resistant to two race mixtures of stem rust and to three race mixtures of leaf rust, at seedling stage. These resistances were confirmed in adult stage, under natural (field) infection conditions. The line 2 presented as moderately resistant to powdery mildew, under field conditions. The lines 11 (Backa/Alondra), 15 and 21 (Capitole/Bluetit), 16 (Sava/4/Tezanos Pintos Precoz// I/IRN 46/CIANO/3/Protor) and 17 (Vogel Selection 29/Vogel Selection 59$-8881 / /$ INIACaprock/3/Cuckoo) were the most tolerant to $\mathrm{A}^{3+}$ toxicity, but in a lower degree than that exibited by the cultivars BH-1146 and IAC-18.

Index terms: wheat, cultivars, inbred lines; grain yield; plant height; stem and leaf rusts; tolerance, aluminum toxicity.

\section{INTRODUÇÃO}

O acamamento associado ao porte alto das plantas foi um sério problema encontrado pelo Centro Internacional de Melhoramento de Milho e Trigo (CIMMYT), México, para aumentar o potencial de produção das variedades mexicanas, no início dos anos sessentas. Uma solução para esse problema foi encontrado no cultivar Norin 10, que possuía genes para nanismo; tais genes não somente reduziram o porte das plantas como resultaram em maior perfilhamento, mais grãos por espiga e por metro quadrado, uso mais eficiente de fertilizante e água e maior 
Indice de colheita. Entre 1960 e 1980, o México lançou 39 variedades de trigo, todas contendo os genes de nanismo do 'N̦orin 10' e com o potencial de produção de $7.500 \mathrm{~kg} / \mathrm{ha}$, em condição de irrigação (HANSON et al., 1982).

Cultivares de origem mexicana, selecionados em solos com pH próximo da neutralidade, foram recomendados aos agricultores paulistas, a partir de 1970 (CAMARGO, 1972; CAMARGO et al., 1974; FELÍCIO et al., 1976; CAMARGO \& FELÍCIO, 1986, e CAMARGO et al., 1988), pelo alto potencial produtivo, aliado a porte baixo, resistência ao acamamento e às ferrugens somente para solos corrigidos, devido à elevada sensibilidade desses cultivares ao $\mathrm{Al}^{3+}$, presente no solo. Para tais condições, foram lançados os cultivares IRN 526-63, Sonora-63, IRN 152-63, LA-1434, Pitic-62, Tobari-66, INIA-66, Jupateco-73, Alondra-S-46 e, mais recentemente, Anahuac, IAC-161, IAC-162 e IAC-287. Mesmo em solos corrigidos, em anos secos, quando há necessidade de o sistema radicular das plantas aprofundar-se no solo em busca de água, os cultivares mexicanos não têm mostrado bom comportamento, pois apresentam restrição do crescimento das raizes no subsolo, pela presença do Al $^{3+}$ (CAMARGO \& OLIVEIRA, 1981, CAMARGO \& FELÍCIO, 1988).

O programa do melhoramento de trigo do Instituto Agronômico tem procurado, através de cruzamentos entre cultivares nacionais adaptados às condições de solo ácido e cultivares semi-anões de origem mexicana, desenvolver cultivares de porte semi-anão, de alto potencial produtivo e com tolerância à toxicidade de $\mathrm{Al}^{3+}$ (CAMARGO \& FELÍCIO, 1986). Os cultivares IAC-24 e IAC-60 e, mais recentemente, IAC-227, foram lançados, sendo os primeiros a apresentar tais caracteristicas (CAMARGO, 1987; CAMARGO et al., 1985, 1988).

O Instituto Agronômico vem introduzindo anualmente coleções de variedades (Screening Nurseries) e populações híbridas do CIMMYT e da Universidade Estadual de Oregon, visando detectar fontes de resistência à ferrugem-do-colmo (Puccinia graminis f. sp. tritici) e da-folha (Puccinia recondita f. sp. tritici), para utilizar no programa de melhoramento, uma vez que a maioria dos cultivares atualmente recomendados para as diferentes regiões tritícolas paulistas é suscetível a, pelo menos, uma raça dessas ferrugens, necessitando, pois, controle com fungicidas em anos favoráveis ao seu desenvolvimento (SÃO PAULO,1984-89).

O presente trabalho tem por objetivo avaliar as linhagens obtidas por seleções realizadas em populações híbridas, provenientes de cruzamentos entre trigos de inverno e de primavera, introduzidos da Universidade Estadual de Oregon, em comparação com os cultivares BH-1146, IAC-18 e Alondra-S-46, em diferentes locais paulistas, quanto à produção de grãos, características agronômicas, resistência às doenças, principalmente à ferrugem-do-colmo e da-folha, e tolerância à toxicidade de alumínio, visando à escolha das mais promissoras para multiplicação e posterior lançamento aos triticultores, ou utilizá-las como fontes genéticas de interesse no programa de cruzamentos do Instituto Agronômico. 


\section{MATERIAL E MÉTODOS}

Foram incluídas nos ensaios vinte e duas linhagens cujos cruzamentos são descritos a seguir:

Linhagens

1

2

3 e 4

5

6$$
7
$$

8

9

$10,11,12$ e 13

$14,15,18,19,20$ e 21 16

17

22

Cruzamentos

- Novi Sad 738/Bluejay.

- Leonardo 23/Bluejay.

-Yaktana54/Norin10-Brevor//Narino/59/3/Hyslop/4/

/CIANO/Gallo.

-Nainari 60/Dijon/Nogel Selection/3/l150-18/4/Santa Catalina/5/Kalian/Bluebird.

- Agri/Mochis 73.

- Bragado/Pavon 76.

- S 13//Aobakomughi/Pavon 76.

- Pumafen/Lilifen//Alondra.

- Backa/Alondra.

- Capitole/Bluetit.

- Sava/Tezanos Pintos Precoz//IRN 46/CIANO/3/Protor.

- Vogel Selection 29/Vogel Selection 58-8881//INIA

/Caprock/3/Cuckoo.

- Pitic 62/Mazoe//CIANO/3/Lilifen/4/Sol.

Como controles, utilizaram-se os seguintes cultivares: $\mathrm{BH}-1146$ e IAC-18, de porte alto, suscetíveis aos agentes causais da ferrugem-do-colmo e da-folha, ciclo precoce e tolerantes à toxicidade de $\mathrm{Al}^{3+}$, bem como Alondra-S-46, de porte semi-anão, resistente à ferrugem-do-colmo, porém suscetível à ferrugem-da-folha e moderadamente sensível à toxicidade de $\mathrm{Al}^{3+}$. A origem desses cultivares é a seguinte:

'BH-1146' - Selecionado no Instituto Agronômico de Minas Gerais, Belo Horizonte, sendo proveniente do cruzamento entre o híbrido 'Ponta Grossa' $x$ 'Fronteira', com o 'Mentana'.

'IAC-18' - Oriundo da seleção de progênies do híbrido 411, originado do cruzamento entre o 'BH-1146' e o 'S-12', proveniente da Secretaria da Agricultura do Rio Grande do Sul, seguido de três retrocruzamentos para o 'BH-1146'.

'Alondra-S-46' - Selecionado pelo Centro Internacional de Melhoramento de Milho e Trigo, a partir do cruzamento (D6301/Nainari 60//Weique Red Mace/3/ClANO $67^{*} 2$ Chris), e introduzido pelo Centro Nacional de Pesquisa de Trigo, EMBRAPA, onde foi submetido a novo processo de seleção. 
Utilizou-se o delineamento estatístico de blocos ao acaso, com três repetições por local. Cada ensaio foi constituído de 75 parcelas, cada uma formada de cinco linhas de $3 \mathrm{~m}$ de comprimento, espaçadas de $0,20 \mathrm{~m}$. Deixou-se uma separação lateral de $0,60 \mathrm{~m}$ entre as parcelas. A semeadura foi feita na base de 80 sementes viáveis por metro linear de sulco, equivalendo a 1.200 sementes por parcela, com uma área útil de colheita de $3 \mathrm{~m}^{2}$.

Em 1984, semeou-se um ensaio na Estação Experimental de Mococa. Em 1985, dois ensaios: um na Estação Experimental de Tatul e outro no Centro Experimental de Campinas. Em 1986, foram efetuados dois ensaios: na Estação Experimental de Tatul e na Fazenda Nossa Senhora da Penha, município de Florínea. Em 1987, semeou-se um ensaio, na Estação Experimental de Tatul.

Os resultados analticos das amostras compostas dos solos dos locais estudados encontram-se no quadro 1.

Todos os experimentos foram efetuados com irrigação por aspersão, coletando-se os dados seguintes:

Ferrugem-do-colmo e da-folha: Efetuou-se a avaliação dessas doenças causadas, respectivamente, por Puccinia graminis f. sp. tritici e $P$. recondita, através de observação geral, em cada parcela, no colmo e nas folhas superiores das plantas, no estádio de inicio de maturação, em condições naturais de infecção. Empregou-se a escala modificada de Cobb, para avaliação da resistência no Ensaio Internacional de Ferrugem do Trigo de Primavera ("International Spring Wheat Rust Nursery"), de SCHRAMM et al. (1974). Essa escala vai de 0 a 99\% de área foliar infectada, complementada pelo tipo de reação: $S$ = suscetivel (uredossoro grande, coalescente, sem necrose e sem clorose); $M S$ = moderadamente suscetivel (uredossoro médio); $M=$ intermediário (diversos tipos de reação); $M R=$ moderadamente resistente (uredossoro pequeno); $R$ = resistente (uredossoro minúsculo, rodeado de áreas necróticas).

Oídio: Avaliação de oídio causado pelo fungo Erysiphe graminis sp. tritici foi feita em cada parcela no estádio de planta adulta, em condições naturais de infecção, empregando-se uma escala (MEHTA, 1978), de 0 a 99\% de área infectada; zero é considerado imune; 1 a 5\%,resistente; 6 a 25\%, moderadamente resistente; 26 a $50 \%$, suscetivel, e 51 a $99 \%$, altamente suscetivel.

Ciclo da emergência ao florescimento: Fazendo-se contagens por parcela individual do número de dias decorridos da emergência das plântulas até o pleno florescimento.

Plantas acamadas: Atribuindo-se notas de 0 (nenhuma planta acamada) a 5 ( $100 \%$ de plantas acamadas) em cada parcela, por avaliação visual próxima da época de maturação. 


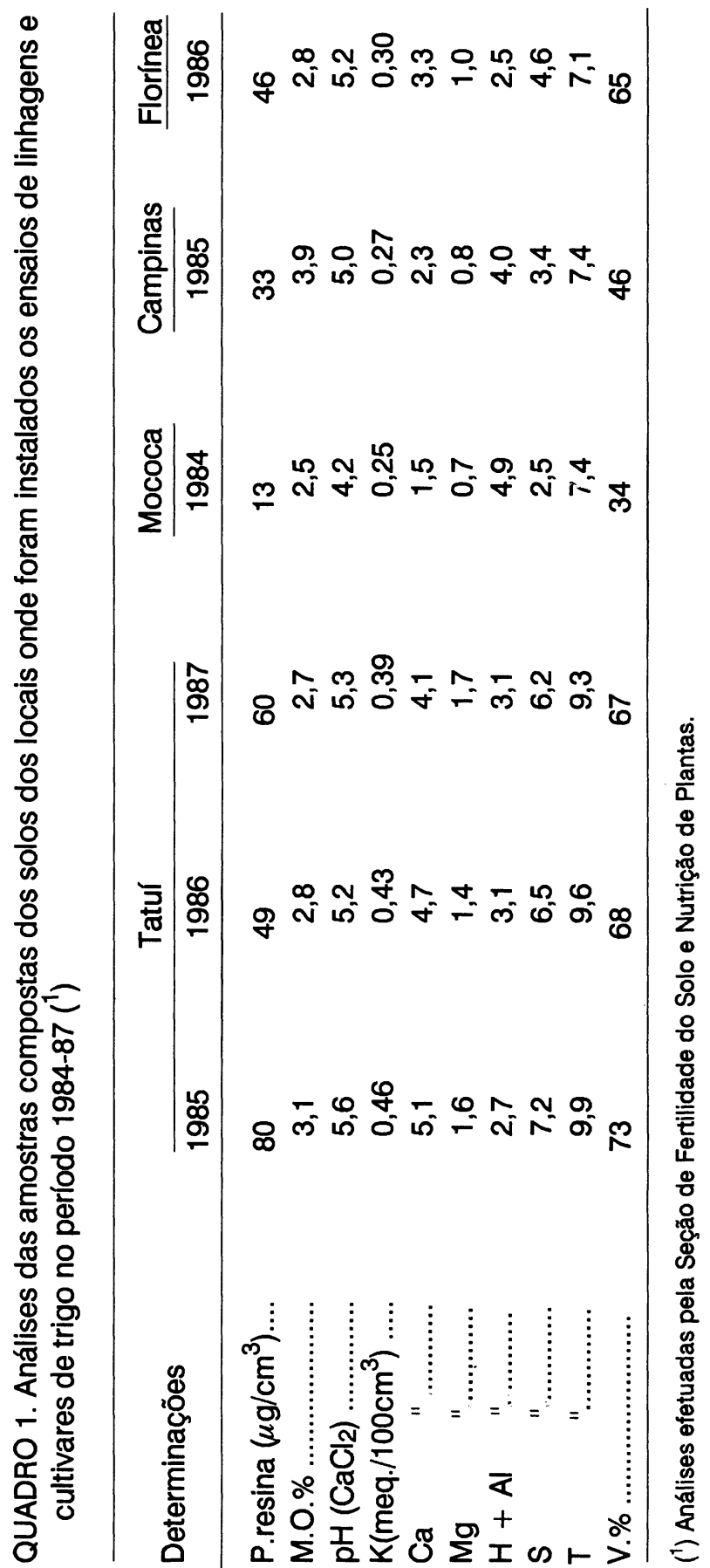


Altura das plantas: Medida no campo, na época de maturação, a distância, em centímetros, do nível do solo ao ápice da espiga, com exclusão das aristas, estimando a média de diferentes pontos de cada parcela.

Produção de grãos: Pesando, em gramas, a produção total de grãos de cada parcela, a qual foi transformada em quilograma/hectare.

As características produção de grãos e altura das plantas em cada um dos seis ensaios e ciclo da emergência ao florescimento somente nos ensaios de Mococa (1984), Campinas (1985) e Florínea (1986) foram submetidas à análise da variância, utilizando-se o teste $F$ ao nivel de $5 \%$ para detectar efeitos significativos de genótipos e repetições. Efetuaram-se análises da variância conjunta para os experimentos de Tatul e para os seis experimentos, independentemente dos locais onde foram instalados, para produção de grãos, visando detectar, pelo teste $F$ ao nível de $5 \%$, as significâncias dos efeitos de experimentos, genótipos e interação genótipos $\mathrm{x}$ experimentos. A comparação das médias dos genótipos para as características estudadas foi feita pelo teste de Tukey ao nivel de 5\%. 0 mesmo teste de média foi empregado para a comparação dos genótipos nos grupos de experimentos, usando-se como estimativa do desvio padrão residual o quadrado médio da interação genótipos $x$ experimentos da análise da variância.

As sementes dos genótipos foram remetidas ao Centro Nacional de Pesquisa de Trigo, para identificação, quanto à resistência em estádio de plântula, em condições de casa de vegetação, a duas misturas de raças de Puccinia graminis f. sp. tritici, agente causal da ferrugem-do-colmo (mistura 1: raças G15, G17, G18, G19, G20 e G21, e mistura 2: raças G22, G23 e G24) e a três misturas de raças de $P$. recondita f. sp. tritici, agente causal da ferrugem-da-folha (mistura 1: raças B27 e B29; mistura 2: raças B30, B31 e B32, e mistura 3: raças B25, B26, B27, B29, B30, B31, B32 e B33), de ocorrência comum no Brasil (BARCELLOS, 1986, e COELHO, 1986).

As plântulas das linhagens e dos cultivares foram testadas em condições de laboratório, para tolerância a $0,2,4$ e $6 \mathrm{mg} /$ /itro de $\mathrm{Al}^{3+}$ em soluções nutritivas, conforme CAMARGO \& OLIVEIRA (1981), CAMARGO et al. (1987) e MOORE et al. (1976). O delineamento estatístico empregado foi o de blocos ao acaso com parcelas subdivididas, sendo as parcelas compostas por quatro concentrações de alumínio e as subparcelas, pelos genótipos de trigo. Foram feitas duas repetições para cada solução de tratamento. Analisaram-se os dados, considerando-se a média de comprimento da raiz primária central das dez plântulas de cada genótipo, em 72 horas de crescimento nas soluções nutritivas completas sem alumínio, que se seguiu a 48 horas de crescimento nas soluções de tratamento contendo quatro concentrações de alumínio. 


\section{RESULTADOS E DISCUSSÃO}

Os quadradros médios das análises da variância individual, das produções de grãos, dos genótipos estudados, em diferentes regióes paulistas, em 1984-87, encontram-se no quadro 2. Os dados mostraram efeitos significativos ao nivel de $5 \%$ para genótipos nos seis experimentos e para repetições somente nos ensaios de Mococa (1984), Campinas (1985) e Tatur (1985 e 1987).

Os quadrados médios da análise da variância conjunta das produções de grãos dos genótipos avaliados nos três experimentos de Tatur (1985-87) são apresentados no quadro 3: houve efeitos significativos para experimentos, genótipos e repetições dentro de experimentos, e não significativos para a interação genótipos $x$ experimentos. São também apresentados os quadrados médios da análise da variância, para a mesma característica, dos genótipos estudados nos seis ensaios, no período 1984-87. Verificaram-se efeitos significativos ao nivel de $5 \%$ para experimentos, genótipos, repetições dentro de experimentos, e interação genótipos $\mathrm{x}$ experimentos.

Através do teste de Tukey aplicado ao nivel de $5 \%$ para a comparação das médias de produção de grãos dos genótipos nos três ensaios de Tatuí-Quadro 4 observou-se que a linhagem 1, que produziu $2.925 \mathrm{~kg} / \mathrm{ha}$, foi a mais produtiva, diferindo, porém, somente das linhagens 6, 8, 13, 14 e 15. Destacou-se, também, quanto à produção de grãos nessas condições, o cultivar BH-1146 (2.857 kg/ha).

No ensaio em condição de solo ácido de Mococa, em 1984, com porcentagem de saturação por bases de 34 (Quadro 1), sobressaíram-se, quanto à produção de grãos (Quadro 4), os cultivares BH-1146 (1.878kg/ha) e IAC-18 $(1.911 \mathrm{~kg} / \mathrm{ha})$, tolerantes à toxicidade de $\mathrm{Al}^{3+}$ (CAMARGO \& OLIVEIRA, 1981, e CAMARGO et al., 1987), os quais não diferiram somente das linhagens $3,4,5,9$, $14,16,18,19$ e 22. Nesse ensaio, observou-se um coeficiente de variação muito alto $(33,22 \%)$, o que tem sido característico de experimentos instalados em solos com elevado teor de $\mathrm{Al}^{3+}$ (CAMARGO et al., 1985).

No ensaio de Campinas, em 1985 (Quadro 4), destacou-sea linhagem 3, com $3.417 \mathrm{~kg} / \mathrm{ha}$, diferindo, porém, ao nivel de $5 \%$, somente das linhagens 10 e 15 . Em Florínea, em 1986, a linhagem 13 foi a mais produtiva (2.006kg/ha), diferindo das linhagens 3, 5, 6, 9, 15, 17 e 21 e do cultivar Alondra-S-46 (Quadro 4).

Considerando-se as produções médias dos genótipos nos seis ensaios nos diferentes locais, em 1984-87, verificou-se, pelo teste de Tukey, ao nivel de $5 \%$, que a linhagem $1(2.403 \mathrm{~kg} / \mathrm{ha})$ e o cultivar BH-1146 $(2.395 \mathrm{~kg} / \mathrm{ha})$ foram os mais produtivos, diferindo significativamente, porém, apenas das linhagens 6 e 15, as menos produtivas. Esses resultados indicam que $\mathrm{O}$ ' $\mathrm{BH}-1146$ ' foi um dos mais estáveis quanto à produção de grãos, confirmando trabalhos de FERREIRA FILHO et al. (1990) e CAMARGO et al. (1989). Sem diferir estatisticamente das demais, destacaram-se também, quanto à produtividade, na média dos seis experimentos, as linhagens 3 e 19 e o cultivar IAC-18 com produções de $2.217,2.219$ e $2.214 \mathrm{~kg} / \mathrm{ha}$ respectivamente (Quadro 4). 


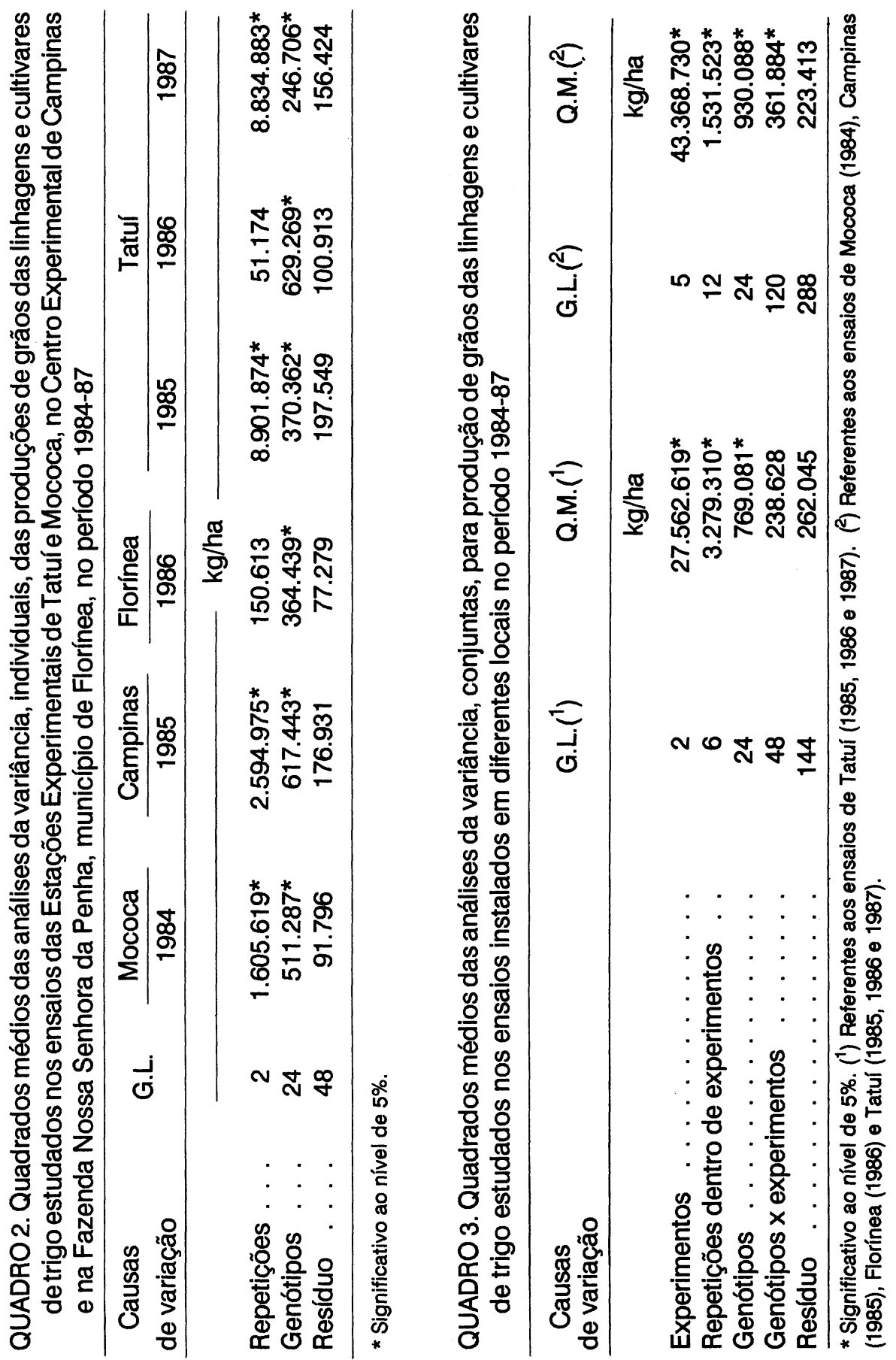




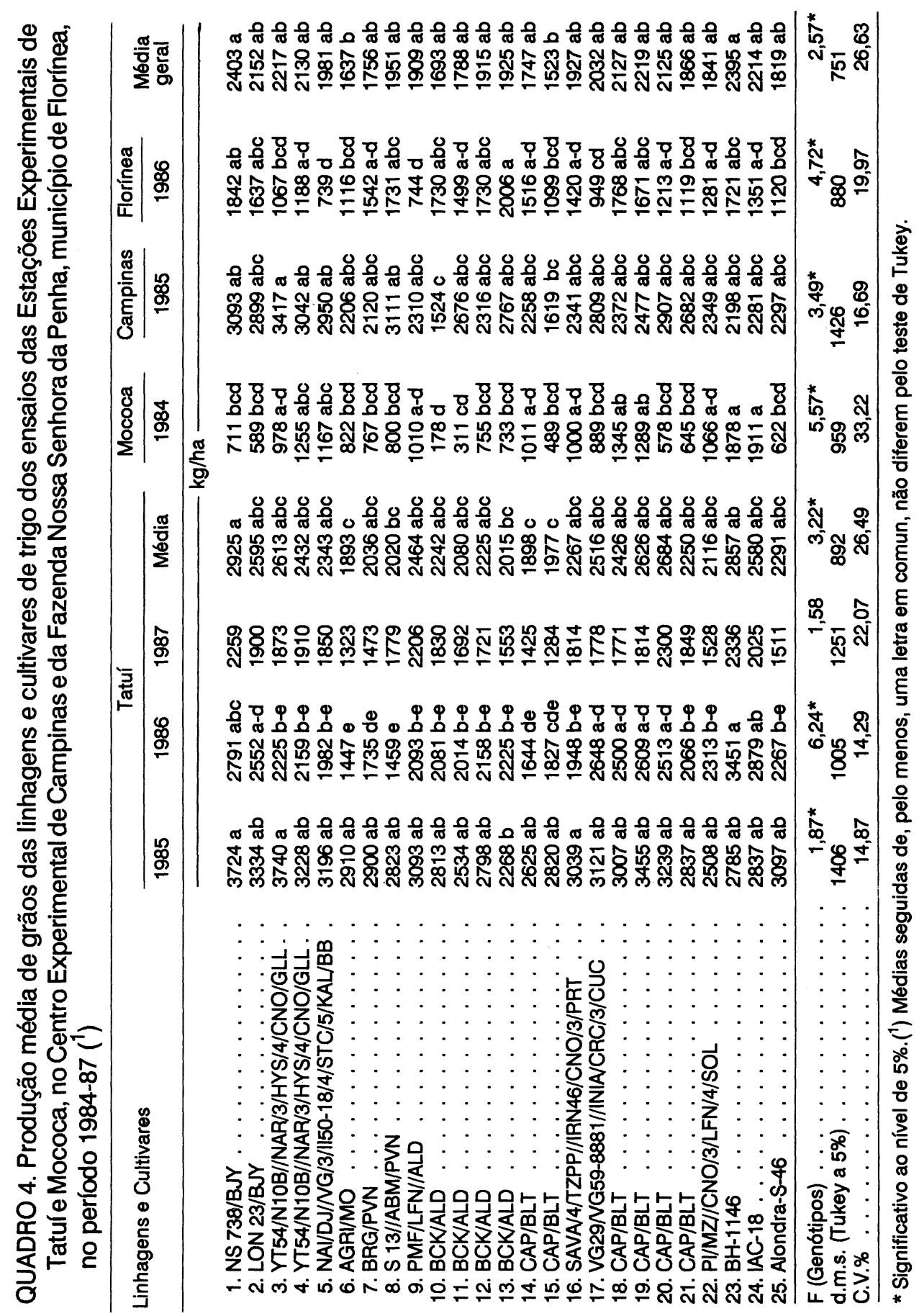


Os graus médios de infecção de ferrugem-do-colmo, ferrugem-da-folha e oídio, nos genótipos de cada experimento, em 1984-87, acham-se no quadro 5.

Em relação à ferrugem-da-folha, destacaram-se, quanto à resistência em planta adulta, as linhagens 2 e 10, que se mostraram imunes, e as linhagens 1 e 13, com reações máximas de $20 \mathrm{MS}$ e $20 \mathrm{~S}$ respectivamente.

Nas mesmas condições, as demais linhagens foram suscetiveis à ferrugem-da-folha, exibindo, pelo menos em um dos experimentos, um grau de infecção variável entre $30 \mathrm{~S}$ e $80 \mathrm{~S}$.

Não houve, no período, condições naturais favoráveis para infecção do agente causal da ferrugem-do-colmo. Somente no ensaio de Tatul (1986), houve ocorrência dessa ferrugem: as linhagens $2,8,9,10,11,13,15$ e 22 foram imunes ao patógeno e as linhagens 4 e 5 apresentaram maior suscetibilidade, com grau de infecção máximo de 20 S.

Em relação ao oídio, destacou-se quanto à resistência em planta adulta no ensaio de Campinas (1985) a linhagem 2, que se mostrou moderadamente resistente a essa doença. Os demais genótipos mostraram-se suscetiveis ou altamente suscetíveis, com graus máximos entre 40 e 80 .

As reações das linhagens e cultivares (estádio de plântula) a Puccinia graminis e $P$. recondita, em casa de vegetação, encontram-se no quadro 6 . As linhagens $2,9,10,13$ e21 foram resistentes às duas misturas de raças prevalecentes do agente causal da ferrugem-do-colmo. Considerando que essas linhagens estavam entre as mais resistentes a esse patógeno, em condições naturais de infecção no campo, constituíram-se, portanto, em fontes genéticas de resistência à ferrugem-do-colmo, do programa de cruzamentos do Instituto Agronômico. As linhagens 2 e 10 mostraram-se resistentes às três misturas de raças prevalecentes do agente causal da ferrugem-da-folha, em estádio de plântula, confirmando a resistência mostrada a essa doença em condições de campo, constituindo fontes genéticas de valor ao programa de melhoramento. As linhagens 9, 13, 15 e 16 mostraram-se suscetíveis somente à mistura de raças 3 , e a linhagem 12 revelou suscetibilidade somente à mistura de raças 1 da ferrugem-da-folha. As linhagens 2 e 10, pela resistência à ferrugem-do-colmo e da folha, em estádio de plântula, em casa de vegetação, e em estádio de planta adulta, no campo, foram consideradas fontes genéticas de valor visandoà introdução dessa resistência nos germoplasmas de trigo atualmente cultivados no Estado de São Paulo, os quais, em sua maior parte, são suscetíveis, principalmente à ferrugem-da-folha. Sendo também moderadamente resistente ao oídio, a linhagem 2 deveria ser preferida nos cruzamentos por, ao mesmo tempo, apresentar-se como fonte genética de resistência a três moléstias de importância para a triticultura paulista.

No quadro 7, encontram-se os quadrados médios da análise da variância conjunta para altura das plantas dos genótipos, em diferentes locais, em 1984-87. Os resultados mostraram, para essa característica, efeitos significativos para 


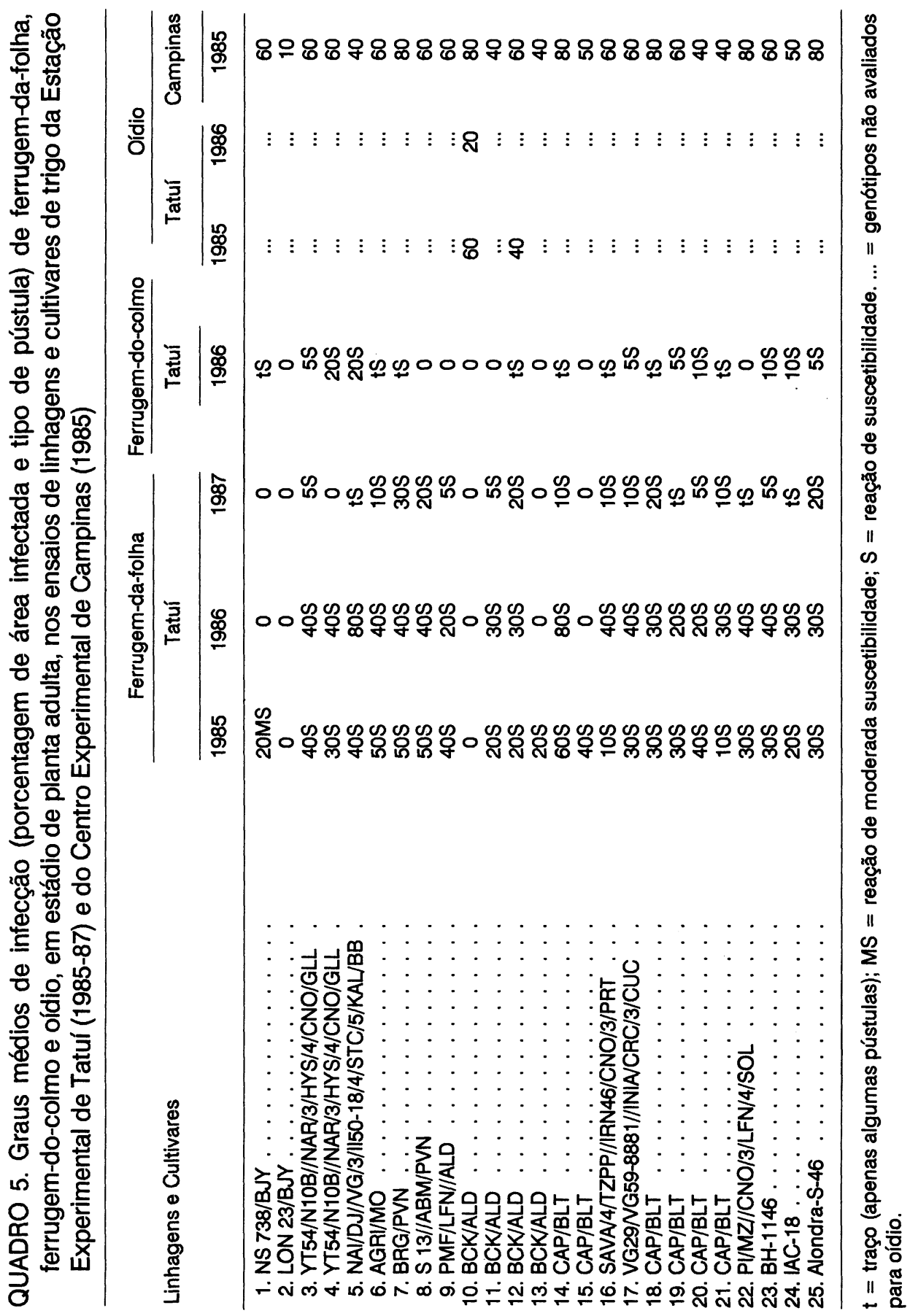




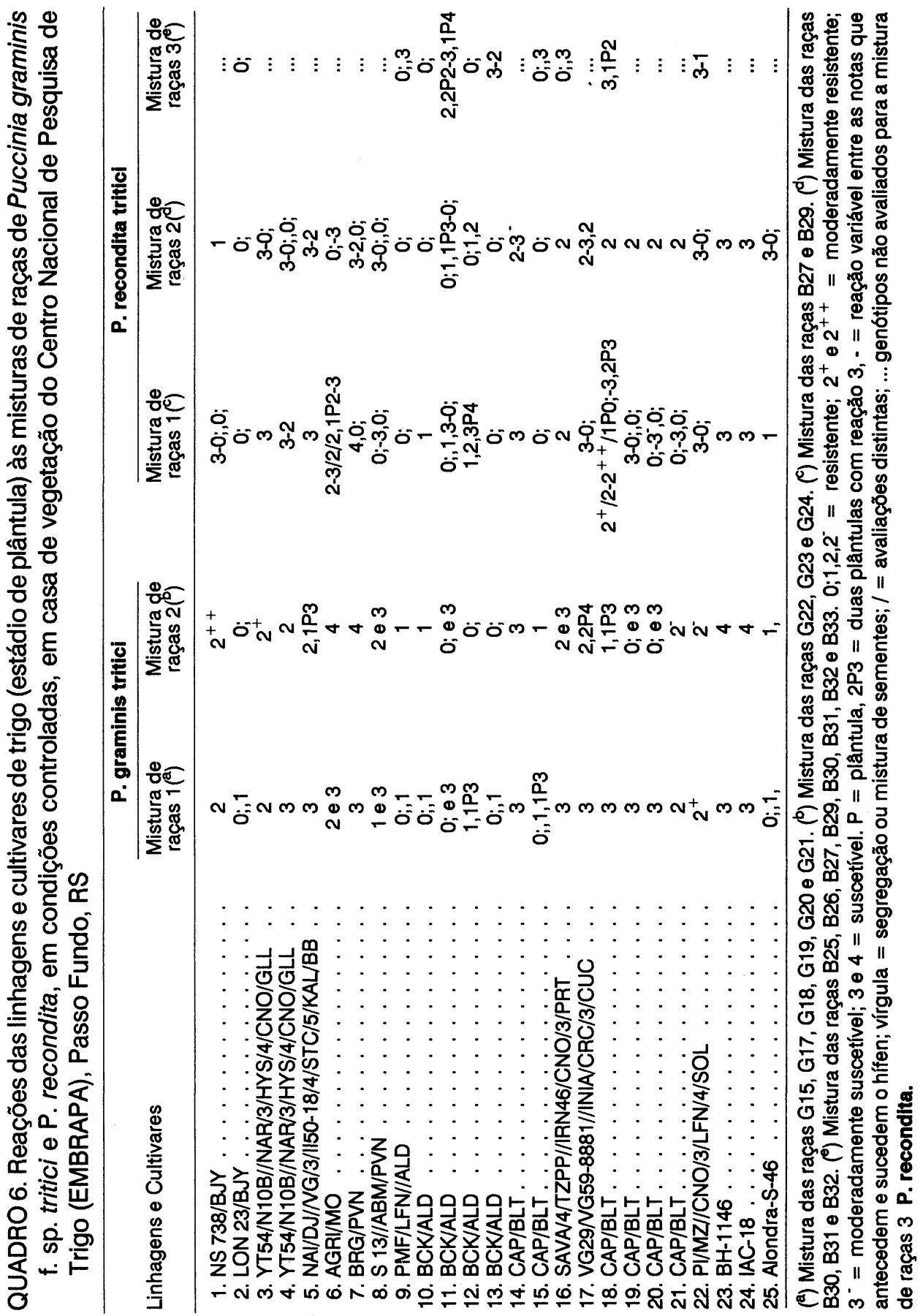




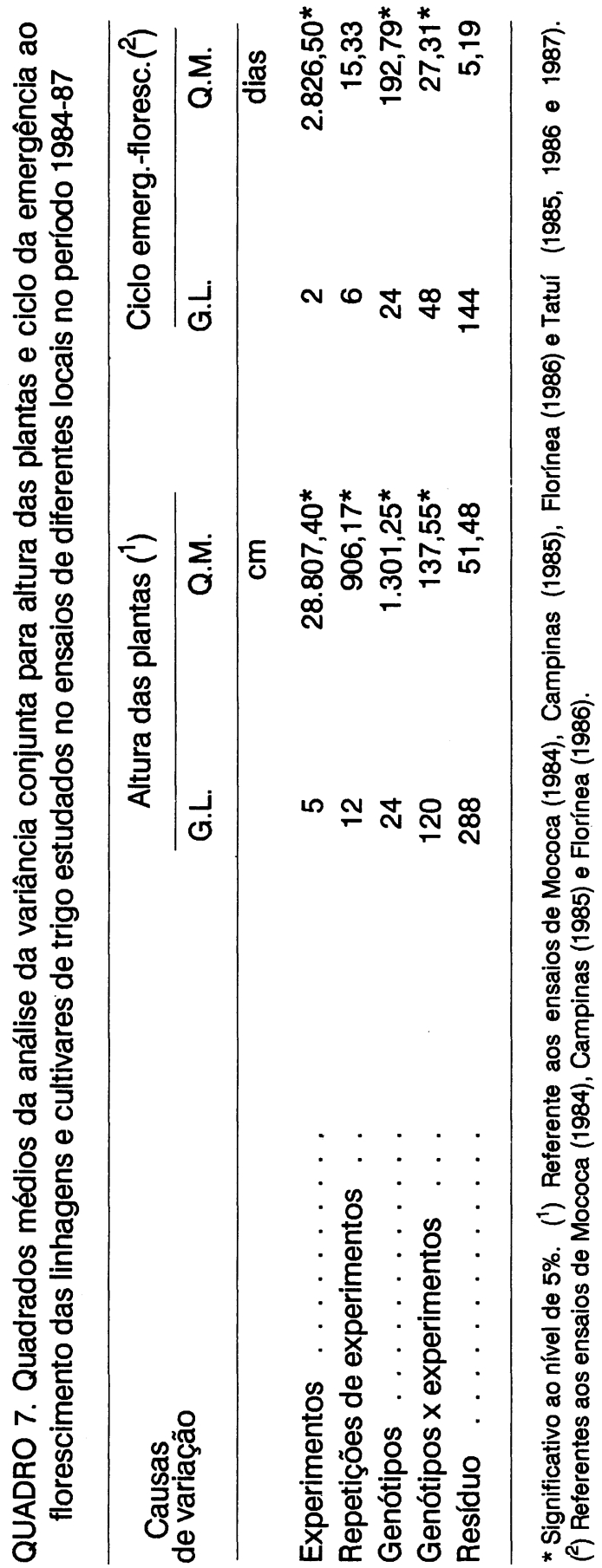


experimentos, genótipos, repetições dentro de experimentos e interação genótipos $x$ experimentos. Nesse quadro, encontram-se, também, os quadrados médios da análise da variância conjunta para ciclo em dias da emergência ao florescimento dos genótipos de trigo nos ensaios da Estação Experimental de Mococa (1984), do Centro Experimental de Campinas (1985) e da Fazenda Nossa Senhora da Penha, em Florínea (1986): para essa característica, houve efeitos significativos para genótipos, experimentos e interação genótipos $x$ experimentos e não significativos para repetições dentro de experimentos.

As alturas médias das plantas dos genótipos de trigo de cada um dos ensaios encontram-se no quadro 8 . As linhagens $1,6,8,10,14,16,17,18,19$ e 20, com as plantas mais baixas, não diferiram do cultivar semi-anão Alondra-S-46, mas, sim, do 'BH-1146', de porte alto. Esses germoplasmas também apresentaram menor porcentagem de plantas acamadas, sendo, portanto, boas fontes de porte baixo para cruzamentos. As linhagens 3, 4, 5, 11 e 22 e os cultivares BH-1146 e IAC-18 apresentaram-se com porcentagem elevada de plantas acamadas - Quadro 9. Essas linhagens que mais acamaram foram, geralmente, associadas a um porte de planta de médio para alto.

O ciclo, em dias da emergência ao florescimento - Quadro 10 - dos genótipos estudados foi médio, não diferindo do apresentado pelo 'Alondra-S-46' (69 dias), fazendo exceção as linhagens 3, 4, 5 e 16 e os cultivares IAC-18 e BH-1146 com ciclo precoce (56-59 dias).

O comprimento médio das raízes de todos os genótipos de trigo, medido após 72 horas de crescimento nas soluções nutritivas completas, que se seguiu a um crescimento de $\mathbf{4 8}$ horas nas soluções de tratamento contendo quatro diferentes concentrações de alumínio, encontram-se no quadro 11.

Na concentração de $2 \mathrm{mg} /$ /itro de $\mathrm{Al}^{3+}$ as linhagens $1,2,3,5,6,9,10,12,13$, 14, 20 e 22 foram sensíveis, isto é, apresentaram uma paralisação irreversivel do meristema apical das raízes após a permanência de 48 horas em soluções nutritivas com essa concentração. Nessas condições, os demais genótipos foram tolerantes.

As linhagens 4, 7, 8 e 18, tolerantes a $2 \mathrm{mg} /$ litro de $\mathrm{Al}^{3+}$ na solução tratamento, exibiram sensibilidade quando nas soluções com $4 \mathrm{mg} /$ litro de $\mathrm{Al}^{3+}$, sendo, portanto, consideradas como moderadamente sensíveis.

A linhagem 19 foi tolerante a $4 \mathrm{mg} /$ /itro de $\mathrm{Al}^{3+}$, porém demonstrou sensibilidade a $6 \mathrm{mg} /$ /itro de $\mathrm{Al}^{3+}$, sendo considerada moderadamente tolerante.

As linhagens 11, 15, 16, 17 e 21, que apresentaram pequeno crescimento radicular na solução nutritiva completa, após $\mathbf{4 8}$ horas em solução de tratamento contendo $6 \mathrm{mg} /$ /itro de $\mathrm{Al}^{3+}$, foram consideradas as mais tolerantes entre as selecionadas das populações híbridas entre trigos de primavera e inverno, introduzidos da Universidade Estadual de Oregon. Em comparação aos cultivares $\mathrm{BH}-1146$ e IAC-18, que exibiram crescimento das raízes de 14,1 e 19,3mm respectivamente, mesmo quando se adicionaram $6 \mathrm{mg} /$ /itro de $\mathrm{Al}^{3+}$ nas soluções de tratamento, essas linhagens apresentaram um grau de tolerância significativamente menor. 


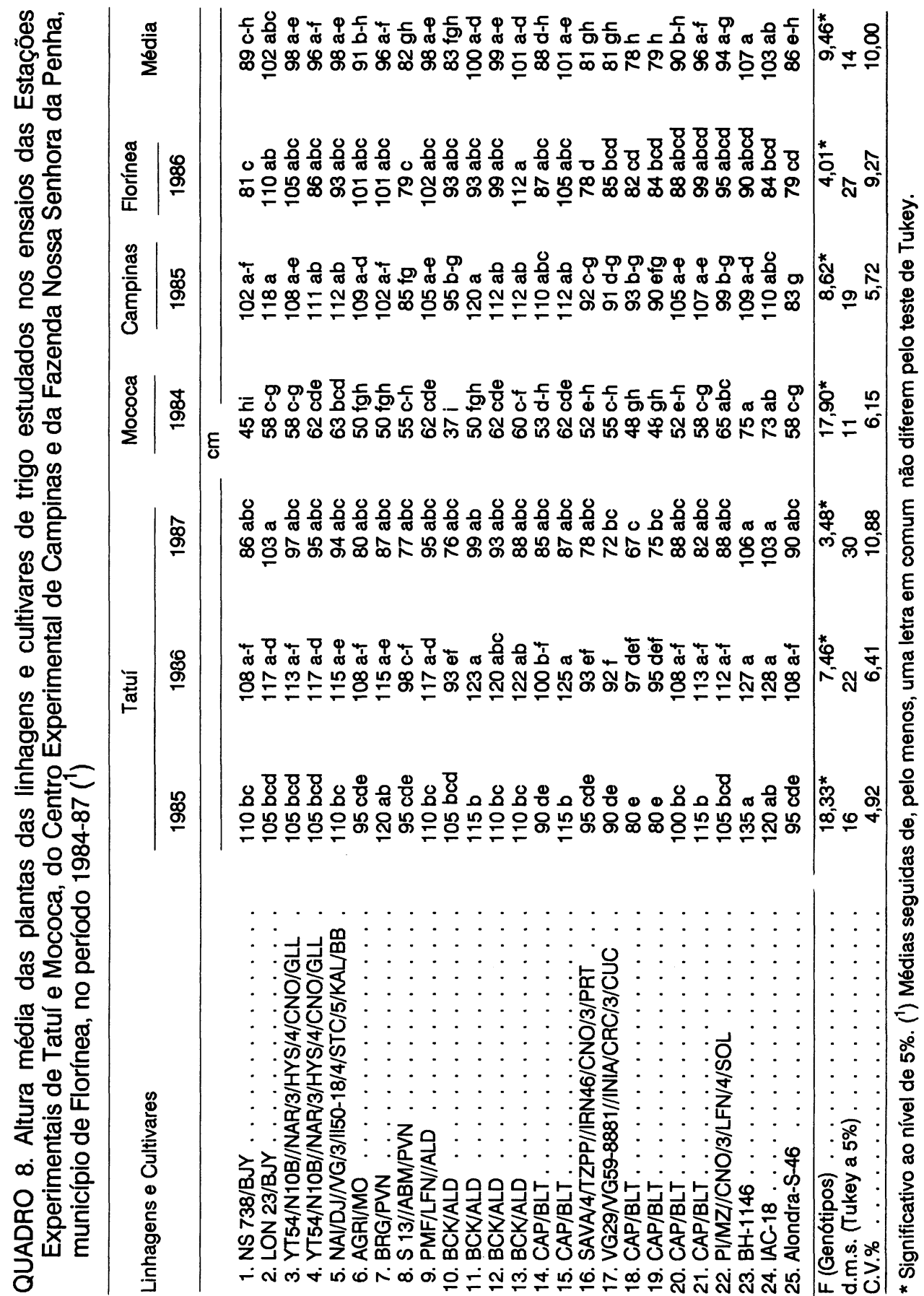




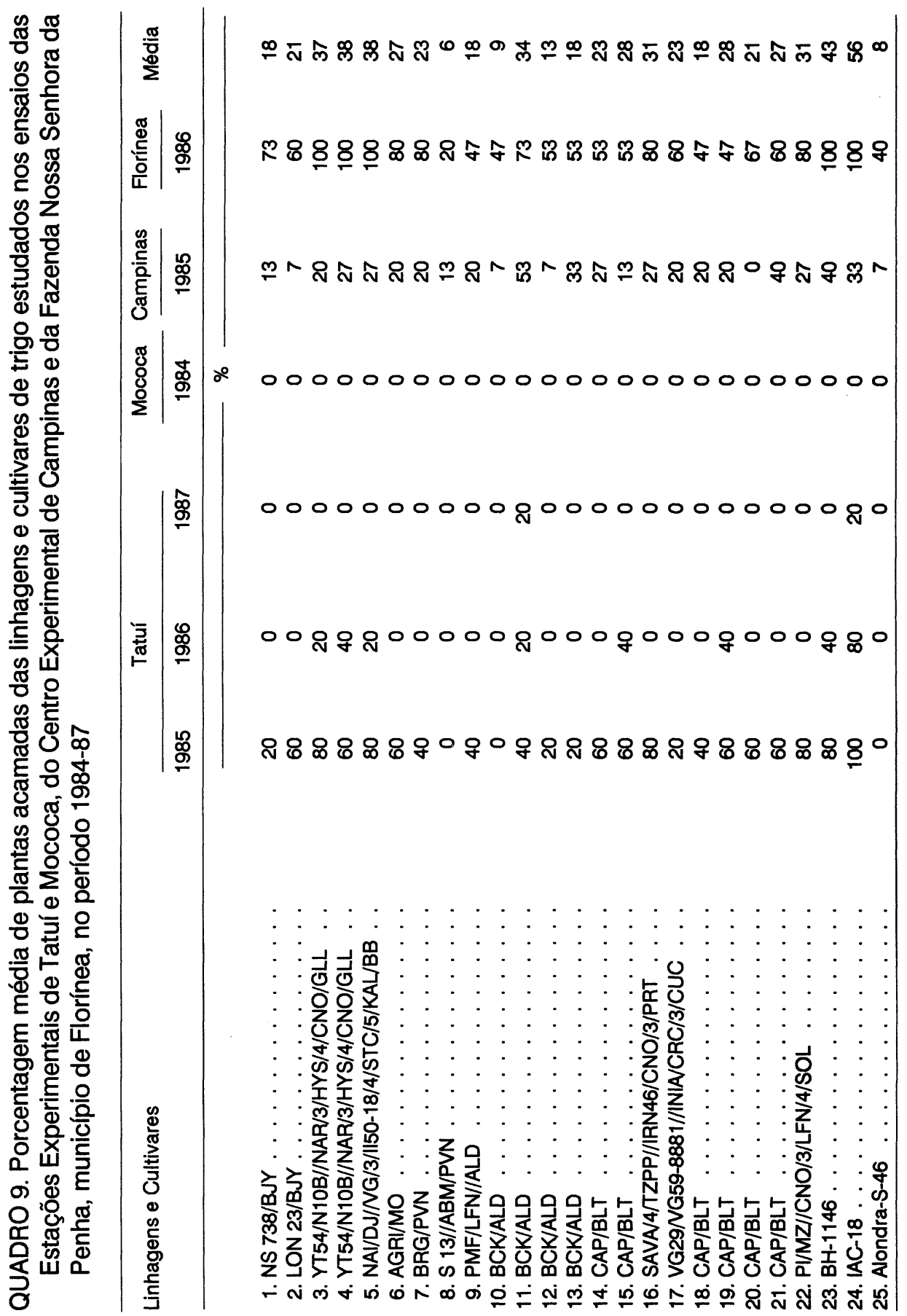




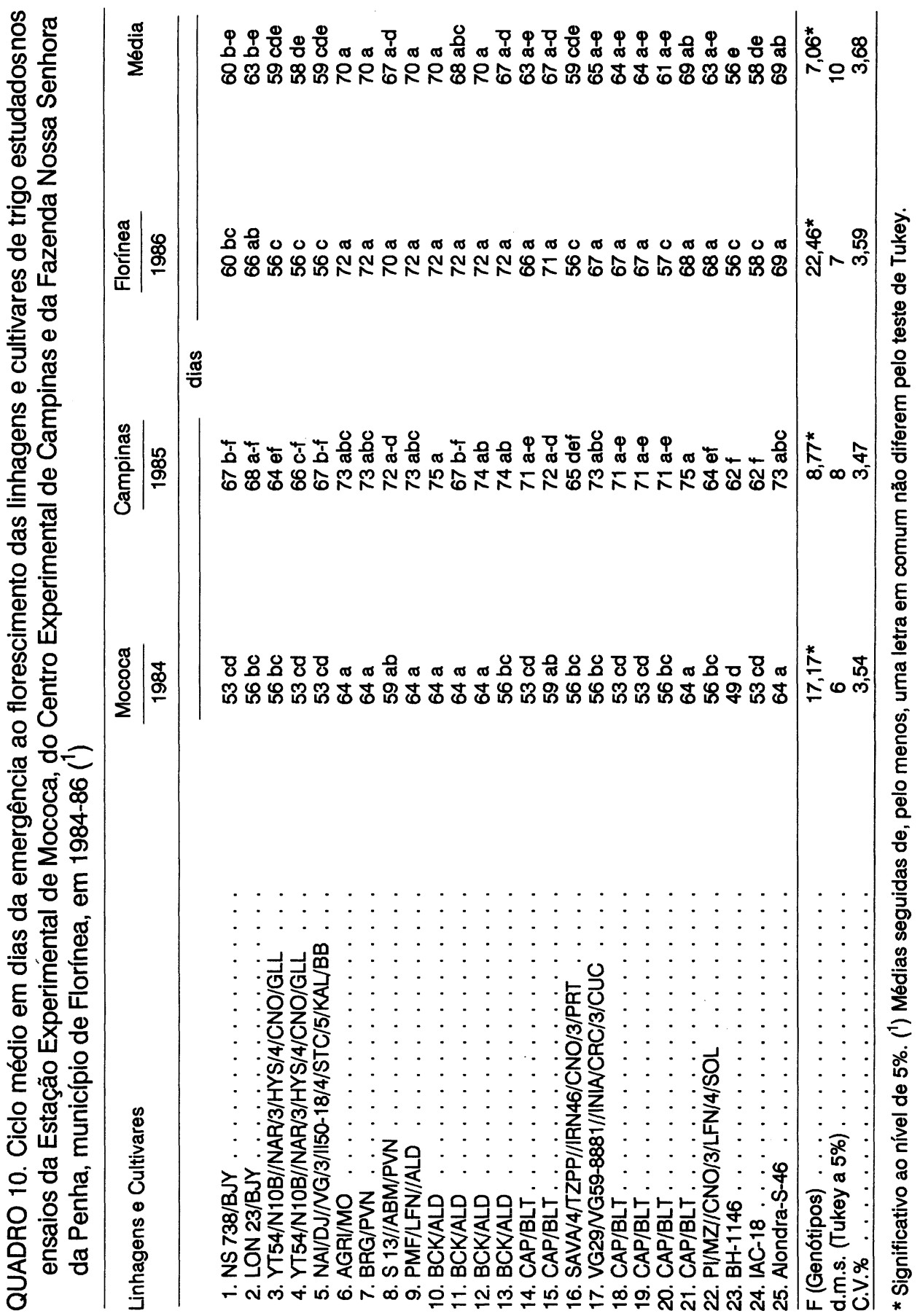




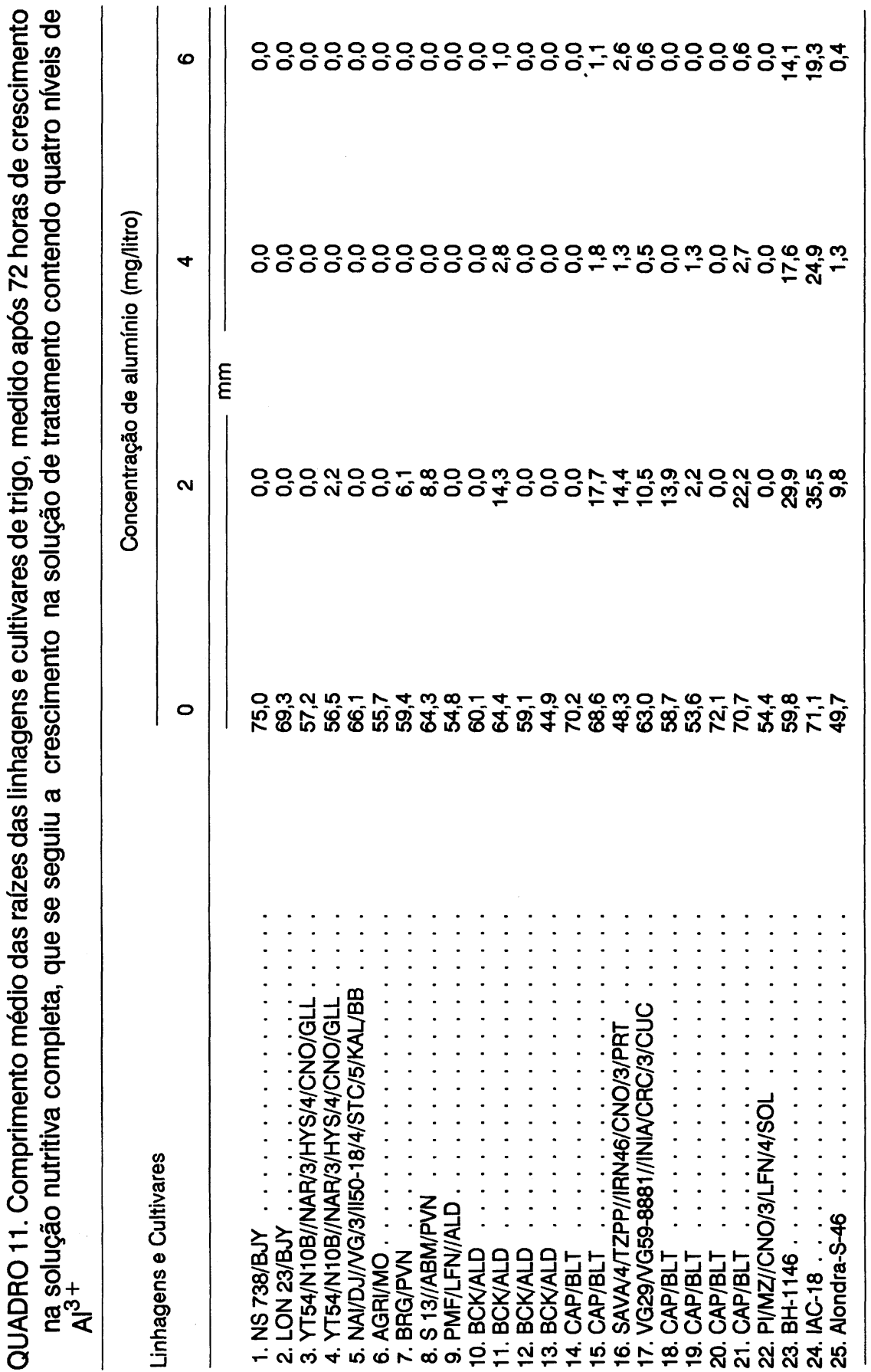


No ensaio de Mococa, em solo ácido (Quadro 1) verificou-se que os cultivares $\mathrm{BH}-1146$ e IAC-18 foram os mais produtivos, devido, em grande parte, à tolerância à toxicidade de $\mathrm{Al}^{3+}$ apresentada. A linhagem 1 , nessas condições, mostrou-se entre as de menor produção de grãos, devido a sua alta sensibilidade à presença de $\mathrm{Al}^{3+}$. Essa linhagem, em Tatul, em solos corrigidos (Quadro 1) mostrou a maior produtividade na média de três anos. Esses dados demonstram a necessidade de ser incorporada a característica tolerância ao $\mathrm{Al}^{3+}$ aos germoplasmas introduzidos de outros centros de pesquisa, para que possam mostrar todo o potencial produtivo, quando cultivado em solos ácidos, na maioria das regiões tritícolas brasileiras.

\section{CONCLUSÕES}

1. Em solos corrigidos da Estação Experimental de Tatú, a linhagem 1 (Novi Sad 738/Bluejay), sensível à presença de $2 \mathrm{mg} /$ /itro de $A \mathrm{I}^{3+}$, em soluções nutritivas, de porte baixo, ciclo precoce, destacou-se quanto à produção de grãos. Em solo ácido da Estação Experimental de Mococa, os cultivares BH-1146 e IAC-18, tolerantes à presença de $6 \mathrm{mg} /$ itro de $\mathrm{A}^{3+}{ }^{3+}$, em soluções nutritivas, de porte alto, ciclo precoce, foram os mais produtivos. As linhagens 1, 3 Yaktana 54/Norin 10-Brevor//Narino 59/3/Hyslop/4/ClANO/Gallo) e 19 (Capitole/Bluetit) e os cultivares $\mathrm{BH}-1146$ e IAC-18 destacaram-se quanto à produção de grãos, considerando-se a média dos seis ensaios avaliados. Essas linhagens deverão ser estudadas em ensaios finais de avaliação visando a um eventual lançamento aos agricultores.

2. As linhagens 2 (Leonardo 23/Bluejay) e 10 (Backa/Alondra) foram resistentes às duas misturas de raças testadas da ferrugem-do-colmo e às três misturas de raças da ferrugem-da-folha em estádio de plântula, em casa de vegetação, confirmando essa resistência em estádio de planta adulta em condição natural de infecção no campo. Esses genótipos se constituíram em fontes genéticas para resistência a tais ferrugens do programa de melhoramento do Instituto Agronômico.

3. A linhagem 2 mostrou-se moderadamente resistente ao oídio, em estádio de planta adulta, em condições naturais de infecção, ao passo que os demais genótipos se apresentaram suscetiveis ou altamente suscetiveis a esse patógeno.

4. As linhagens 11 (Backa/Alondra), 15 e 21 (Capitole/Bluetit), 16 (Sava/4/Tezanos Pintos Precoz//IRN 46/ClANO/3/Protor) e 17 (Nogel Selection 29/Nogel Selection 59-8881//INIA/Caprock/3/Cuckoo) foram as mais tolerantes à toxicidade de $\mathrm{Al}^{3+}$, porém num grau significativamente menor do que $\mathrm{O}$ apresentado pelos cultivares BH-1146 e IAC-18.

\section{AGRADECIMENTOS}

Os autores agradecem ao Centro Nacional de Pesquisa de Trigo (EMBRAPA) a realização dos testes de resistência à ferrugem-do-colmo e da-folha, em casa de vegetação. 


\section{REFERENCIAS BIBLIOGRAFICAS}

BARCELLOS, A.L. Ferrugem da folha e do trigo no Brasil, em 1984 e 1985: ocorrência e virulência. In: REUNIÃO NACIONAL DE PESQUISA DETRIGO, 14., Londrina, 1986. Resultados de pesquisa. Passo Fundo, EMBRAPA-CNPT, 1986. p.117-131.

CAMARGO, C.E.O. de. Estudos de variedades de trigo para o Estado de São Paulo. Piracicaba, ESALQ, 1972. 102p. Tese (Doutorado).

. Melhoramento genético do trigo para irrigação de inverno nas condiçōes do Estado de São. Paulo. In: SIMPOSIO SOBRE O MANEJO DE ÁGUA NA AGRICULTURA, Campinas, 1987. Anais. Campinas, Fundaçăo Cargill, 1987. p.134-174.

; ALCOVER, M. \& ISSA, E. Comportamento de cultivares de trigo em condições de sequeiro no Estado de São Paulo. Bragantla, Campinas, 33:43-53, 1974.

\& FELíCIO, J.C. Melhoramento genético do trigo no Instituto Agronômico. O Agronómico, Campinas, 38(3):213-228, 1986.

\& - Wheat breeding at the Campinas Agronomic Institute. In: WHEAT breeding for acid soils. México, D.F., Centro Internacional de Mejoramiento de Maiz y Trigo, 1988. p.39-49.

- - - FERREIRA FILHO, A.W.P.; FREITAS, J.G. de; BARROS, B. de C.; CASTRO, J.L. de; SABINO, J.C. \& ROCHA JÚNIOR, L.S. Melhoramento do trigo: XXI. Avaliação de linhagens em diferentes regiōes paulistas. Bragantia, Campinas, 48(1):53-71, 1989.

—_ - ; FREITAS, J.G. de: BARROS, B. de C.; CASTRO, J.L. de \& SABINO, J.C. Melhoramento do trigo: XIl. Comportamento de novas linhagens e cultivares no Estado de São Paulo. Bragantia, Campinas, 44(2):669-685, 1985.

-; - - - FERREIRA FILHO, A.W.P.; BARROS, B. de C.; PETTINELLI JÚNIOR, A.; SANTOS, R.R. dos; KANTHACK, R.A.D. \& ROCHA JÚNIOR, L.S. Melhoramento do trigo: XVII. Comportamento de linhagens de origem mexicana no Estado de São Paulo. Bragantia, Campinas, 47(1):25-41, 1988.

\& ROCHA JÚNIOR, L.S. Trigo: tolerância ao alumínio em solução nutritiva. Bragantia, Campinas, 46(2):183-190, 1987.

\& OLIVEIRA, O.F. de. Tolerância de cultivares de trigo a diferentes níveis de alumínio em solução nutritiva e no solo. Bragantia, Campinas, 40:21-31, 1981.

COELHO, E.T. Avaliação de resistência à ferrugem do colmo e das cultivares dos ensaios regionais de rendimento de variedades de trigo do Cone Sul (ERCOS). In: REUNIÃO NACIONAL DE PESQUISA DE TRIGO, 14., Londrina, 1986. Resultados de pesquisa. Passo Fundo, EMBRAPA-CNPT, 1986. p.101-110.

FELÍCIO, J.C.; CAMARGO, C.E. de O. \& BARROS, B. de C. Estudo comparativo de cultivares de trigo em latossolo roxo no Estado de São Paulo. Bragantia, Campinas, 35:147-154, 1976.

FERREIRA FILHO, A.W.P.; CAMARGO, C.E. de O.; FELÍCIO, J.C. \& FREITAS, J.G. de. Estabilidade de rendimento de grãos de trigo na região do Vale do Paranapanema, SP. Bragantia, Campinas, 49(1):83-92, 1990.

HANSON, H.; BORLAUG, N.E. \& ANDERSON, R.G. Wheat in the third world. Boulder, Westview Press, 1982. 174p. 
MEHTA, Y.R. Doenças do trigo e seu controle. São Paulo, Agronômica Ceres, 1978. 190p. (Ceres, 20)

MOORE, D.P.; KRONSTAD, W.E. \& METZGER, R.J. Screening wheat for aluminum tolerance. In: WORKSHOP ON PLANT ADAPTATION TO MINERAL STRESS IN PROBLEM SOILS, Beltsville, 1976. Proceedings. thaca, Cornell University, 1976. p.287-295.

SÃO PAULO. Secretaria de Agricultura e Abastecimento. Relatórios do acordo entre a Secretaria de Agricultura e Abastecimento, através do Instituto Agronômico, $\theta$ as Cooperativas Rurals do Vale do Paranapanema. Campinas, 1984-1989. 6v.

SCHRAMM, W.; FULCO, W.S.; SOARES, M.H.G. \& ALMEIDA, A.M.P. Resistência de cultivares de trigo em experimentação ou cultivo no Rio Grande do Sul, às principais doenças fúngicas. Agronomia Sulriograndense, Porto Alegre, 10(1):31-52, 1974. 